\title{
Criação em rede: entrelaçamentos entre processos manuais de criação, "faça você mesmo" e compartilhamento em plataformas digitais
}

Introdução

Dânica Vasques Fagundes Machado ${ }^{1}$ Maria Lúsa Acioli Falcão de Alencar ${ }^{2}$

O TRABALHO FEITO À MÃo É UMA MODALIDADE DE PRODUÇÃO QUE ACOMPANHA O PERCURSO DA PRÓPRIA SOCIEDADE, baseando-se na necessidade de produzir e modificar utensílios, objetos e ferramentas. Seguiu por anos como a principal forma de produção da sociedade, no entanto, o fortalecimento de métodos produtivos industriais levou à defasagem do trabalhador artesão, já que este não fabricava artefatos na mesma velocidade e qualidade reprodutiva das máquinas.

Ao discutir sobre o ofício artesão, Richard Sennett ${ }^{3}$ introduz o artífice, trabalhador que, não importando o campo de atuação, visa um resultado bem-feito e realizado adequadamente. A gênese deste trabalho estaria no desenvolvimento progressivo das habilidades técnicas, lidando com obstáculos e particularidades referentes a este percurso, a utilização de materiais e o respeito a noções de autoridade e hierarquia - especialmente em vista a relações como a de mestre e aprendiz. Por considerar a trajetória necessária para o desenvolvimento da técnica, além de preservar um ritmo de trabalho que respeita os limites do corpo e do material, temos como intrínseco ao trabalho manual um tempo de produção natural e humano. Esta temporalidade está associada à necessidade da contemplação, indo de encontro aos ideais produtivos adotados na conjuntura pós-industrial ${ }^{4}$ - ou informática - contemporânea, que preza pela estandardização, consumo de acumulação e rapidez nas relações.

Byung-Chul Han $^{5}$ e Jonathan Crary $^{6}$ dialogam ao colocar a sociedade atual em um cenário produtivo onde necessidades como o tempo livre, o sono e a contemplação são vistos como secundários. Han destaca, ainda, uma característica dominante da vida contemporânea, a pessoa ou atividade "multitarefas”. Neste processo, entra-se em contato com cada vez mais informações e ocupações, que são realizadas ao mesmo tempo e sem atenção profunda.

Ao longo da história da arte e do design no século XX, movimentos de contracultura surgiram como oposição às mecânicas produtivas estabelecidas pelo sistema vigente - especialmente a produção em série, racionalização e falta de individualidade dos objetos, relacionados aos ideais modernos. Como forma de resistência a estas práticas, prezava-se pela autonomia e particularização no ato de fabricar.

Sugerimos que, de maneira semelhante, o contexto da sociedade contemporânea fez surgir o desejo por ocupações que valorizem o tempo, a experiência em si, a contemplação e o fazer autônomo. O trabalho feito à mão é grande representante deste ideal que, aliado à questão da liberdade de produção, fez surgir movimentos como o "faça você mesmo", tradução da sigla 'diy' - do it yourself.

\footnotetext{
${ }^{1}$ Dânica Vasques Fagundes Machado, Mestre em Comunicação e Semiótica, PUC-SP, Brasil <danicavfm@gmail.com>

${ }^{2}$ Maria Luísa Acioli Falcão de Alencar, Doutoranda em Design, FAU-USP, Brasil <afalencar.marialuisa@usp.br>

${ }^{3}$ SENNET, R. O Artífice. Rio de Janeiro: Record, 2009.

${ }^{4}$ FLUSSER (2011) coloca a Sociedade Pós-Industrial como aquela em que se trabalha com o setor terciário, ou seja, com a produção de informação. Segundo o autor, neste modelo produtivo, o símbolo portador do valor de um objeto é mais importante que suas características físicas, concretas.

${ }^{5}$ HAN, B. C. Sociedade do cansaço. Petrópolis: Vozes, 2015.

${ }^{6}$ CRARY, J. 24/7 - Capitalismo tardio e os fins do sono. São Paulo: Cosac Naify, 2014.
} 
O “faça você mesmo" teve seu início marcado em 1912, como alternativa para reparos e trabalhos domésticos; no entanto, o termo só passou a ganhar força a partir da década de 1970, com a expansão do movimento punk, que propunha autonomia quanto à criação, modificação e conserto de objetos, além do aprendizado de ofícios relacionados. Ademais, o movimento buscava dialogar com questões sociopolíticas, relativas ao consumo, à arte; e incentivava ações, práticas e produções coletivas.

A dinâmica tecnológica e informacional da sociedade em rede ${ }^{7}$, favoreceu a criação de espaços de compartilhamento de experiências, técnicas, ferramentas e serviços. Assim, a comunicação em mídias, aliada ao aumento dos ambientes virtuais e redes sociais no cotidiano das pessoas permitiu a difusão de técnicas manuais e práticas autônomas nas redes sociais, sendo notável a diversidade de conteúdos compartilhados que envolvem o "faça você mesmo". Este fluxo pode refletir uma busca por atividades que permitam o contato direto com os processos de criação, através de tutoriais, relatos dos produtores e dicas de manuseio dos materiais e de ferramentas. Os conteúdos compartilhados revelam as possibilidades do fazer e o como produzir algo, criando novas lógicas de consumo.

Nos campos das artes e do design, as redes sociais são, para os produtores, espaços de divulgação de seus projetos e de compartilhamento dos percursos de criação. Por meio de relatos do processo, conversas sobre os trabalhos e discussões sobre o campo em que atuam, surgem novas formas de se relacionar com o público e consumidores. Para os interessados nos assuntos tratados, são diversos os materiais de teor informativo disponibilizados sobre essas produções.

Neste trabalho, buscamos investigar como se deu, na última década, a popularização de ideais de autonomia, manualidade e "faça você mesmo", especialmente considerando as produções contemporâneas de artes manuais, design e suas relações. Assim, nos atentamos ao papel das tecnologias e da sociedade em rede na consolidação de vínculos entre produtores e consumidores do conteúdo compartilhado. Estes consumidores, em si, podem se tornar novos produtores ao colocarem em prática as informações, técnicas e conhecimentos adquiridos. Buscamos, também, verificar o processo de criação manual atrelado ao compartilhamento em rede, trabalhando com a ideia do "faça você mesmo" como incitador de uma produção local e de nicho. Aliada a ideais de autonomia e um tempo natural de fabricação, está a questão de uma maior consciência no ato do consumo e fortalecimento da economia criativa.

Para investigar os questionamentos levantados, utilizou-se o aporte bibliográfico sobre artesanato, artes, design, o fazer manual, processos de criação, além da cultura das redes e dinâmicas informacionais na sociedade contemporânea. $O$ mapeamento das produções, aliada à coleta e análise de dados, visa trazer informações sobre a popularização das práticas artesanais e do "faça você mesmo" ligados à arte e ao design na sociedade em rede.

Trouxemos, ainda, casos de produtores e coletivos brasileiros que, atualmente, dentro do campo das artes visuais, artes têxteis e design editorial, exemplificam as iniciativas e procedimentos que são compartilhados nas plataformas digitais. Os documentos públicos destes autores, como vídeos dos processos, relatos e tutoriais, ainda que possuam caráter retrospectivo ${ }^{8}$, sugerem a intenção de divulgar o processo como forma de expor o trabalho em si, podendo resultar em novas formas de se relacionar com o público e consumidores.

\section{Trabalho artesanal e tempo de produção}

O artesanato, de maneira geral, é uma modalidade produtiva cujas características variam em diversas culturas e países, e as diferentes visões quanto ao ofício são influenciadas por como se deu e progrediu o processo de industrialização nestas diferentes localidades. Segundo Borges ${ }^{9}$, em países como a Itália e o Japão, o trabalho artesanal serviu como modelo base para o industrial. Em outro caso, no Brasil, houve a ruptura com o feito à mão, pois era visto como herança do subdesenvolvimento

\footnotetext{
${ }^{7}$ Castells, M. A sociedade em rede. São Paulo: Paz e Terra, 2016.

${ }^{8}$ SALLES, C. Crítica genética: fundamentos dos estudos genéticos sobre o processo de criação. São Paulo: EDUC, 2008.

${ }^{9}$ BORGES, A. Design + Artesanato: o caminho brasileiro. São Paulo: Terceiro Nome, 2011.
} 
que supostamente viria a ser superado com a industrialização e o trabalho mecanizado. A autora comenta, ainda, que na América Latina a produção artesanal é atrelada à comunidade, onde os saberes e técnicas são repassados entre gerações.

A figura do produtor artesanal, notadamente, é dotada de habilidade e empenho corporal, já que a capacitação do trabalho é adquirida ao longo do tempo e implica um esforço pessoal. Há a relação entre o pensamento crítico e a técnica para o uso das mãos e ferramentas adjacentes, e, neste sentido, Sennett coloca que "todo artífice sustenta um diálogo entre práticas concretas e ideias" ${ }^{10}$.

Ainda segundo o autor, o trabalho feito à mão traz recompensas emocionais àquele que o realiza, deixando de ser visto como uma atividade mecânica. Primeiramente, estaria o orgulho em se empenhar para realizar algo satisfatório; segundamente, a importância em ver o fruto do trabalho de maneira concreta, tangível.

Outra fonte de satisfação seria a lentidão do trabalho artesanal, a qual permite a consolidação da prática e desenvolvimento das habilidades do produtor. Esta temporalidade propicia, além disto, o exercício da imaginação, contemplação e reflexão ${ }^{11}$ algo que não é possível em processos de fabricação que prezam pela rapidez e eficiência dos resultados.

Para Byung-Chul-Han, a natureza da cultura humana deriva do permitir-se tempo, atenção profunda e contemplação. Nesta questão, estaria o desenvolvimento de campos como a arte e a filosofia. No entanto, prevalece na sociedade contemporânea o emprego da modalidade de atenção a qual o autor chama "hiperatenção" ${ }^{12}$, caracterizada pelo foco em múltiplas atividades, informações e práticas. De fato, é perceptível a difusão de ideais como a produtividade contínua, o trabalho ininterrupto e o consumo exacerbado, resultando no que Crary chama de ambiente 24/7. O padrão 24/7 é caracterizado pelo estímulo à publicidade e profusão de imagens, além da indiferença às necessidades humanas, como o sono, a proteção ou mesmo o lazer. É, segundo o autor, um modelo de desempenho maquínico que exige um alto custo humano.

Diante deste contexto, a adoção de práticas que envolvam a lentidão e o desempenho progressivo representa a fuga ao excesso de estímulos e à autoexploração. A temporalidade poética do trabalho artesanal e a possibilidade de realizar algo com as próprias mãos são contrapontos à impessoalidade do produto industrial massificado e à ideia de uma sociedade multitarefas. Borges ${ }^{13}$ coloca que, ao contrário do que se pensava, a chegada da sociedade tecnológica não implicou no desaparecimento do trabalho artesanal. Parece, na verdade, exacerbar os valores humanos relacionados ao fazer manual e a singularidade dos objetos.

\section{o "faça você mesmo" e a popularização de un fazer manual autônomo}

O termo do it yourself (do inglês, "faça você mesmo") surgiu em 1912, em um artigo sobre decoração na revista americana Suburban Life. O texto, que tratava especificamente sobre papéis de parede, propunha que os leitores aprendessem a manusear o material e criar soluções domésticas que chegassem a resultados desejados, sem a necessidade de um profissional da área ${ }^{14}$. Por volta de 1914 a 1945, o "faça você mesmo" foi utilizado como uma maneira de se referir aos modos de fazer autônomos e de baixo custo, que permitiam reparos domésticos e utilitários. Apesar disso, não era amplamente difundido nem considerado um movimento significativo.

Em meados de 1970, surgiu o movimento punk e, com ele, uma nova cultura urbana. Associado à consciência reflexiva que emergiu nos anos 1960, assim como a insatisfação com ideais estéticos e produtivos que derivam da racionalidade moderna; o movimento se ocupava de questões sociopolíticas, propondo ações pautadas em esforços coletivos, práticas sociais

\footnotetext{
${ }^{10}$ SENNET. Op. cit., 2008, p. 20.

${ }^{11}$ Ibidem, 328.

${ }^{12}$ HAN. C. Op. cit., 2015.

${ }^{13}$ BORGES. Op. cit., 2011, p. 203-204.

${ }^{14}$ HARRIS, R. Building a Market: The Rise of the Home Improvement Industry, 1914-1960. Historical Studies of Urban America. Chicago: University of Chicago Press, 2012.
} 
alternativas e o trabalho autônomo. O fazer com as mãos, antes considerado uma ferramenta prática, passou a ser utilizado também como proposta política de criação, autonomia e cooperação. Por meio disto, o "faça você mesmo" foi associado como um dos pilares do movimento, ganhando forma e passando a criar novos significados para determinados modos de produção.

Para além dos reparos e da criação de alternativas utilitárias, o movimento punk incorporou a ideia do fazer com as próprias mãos em outras esferas de criação, como na produção gráfica, editorial e artística. A manualidade se deu como um caminho autônomo para o desenvolvimento de materiais impressos, sendo uma ferramenta acessível, independente e que permitia a difusão dos ideais do movimento. Cartazes e fanzines possuíam uma linguagem gráfica própria dos materiais e técnicas utilizadas -- a colagem, fotocópia, retícula e stencil, entre outros, que foram gravados no imaginário popular como característicos da cultura visual punk.

Ainda assim, a valorização do fazer manual não se deu apenas no movimento punk e no "faça você mesmo". Outras manifestações pós-modernistas coexistiam à época, compartilhando da mesma necessidade por mudanças socioculturais. No design pós-moderno, tanto de objetos gráficos quanto de mobiliário, apresentava-se um elogio à diversidade e experimentação com cores e texturas ${ }^{15}$. Especialmente no campo gráfico, por meio da mistura entre técnicas manuais - como o desenho, o recorte e a colagem - e a fotografia, o fotolito e a retícula, criavam-se composições híbridas.

Da mesma maneira, nas artes visuais, houve a ressignificação de práticas manuais por determinadas artistas feministas, que propunham o uso de técnicas artesanais têxteis visando questionar os padrões da época. O bordado, a costura, o crochê e outros ofícios considerados femininos e de âmbito doméstico foram usados para reivindicar espaços e fortalecer a arte feita por mulheres.

Seguindo esta corrente, ainda nos anos 1970, o cenário brasileiro presenciou o crescimento e valorização das práticas manuais associadas às tradições artesanais e populares da cultura do país, principalmente as práticas têxteis. Esses artistas buscavam, através desta maneira de produzir, contestar e questionar os modelos de fabricação vigentes - da industrialização e falta de individualização. Ademais, a revalorização do artesanato por tais artistas também estava relacionada ao prazer de fazer ${ }^{16}$.

Trazendo um contexto social contemporâneo, especialmente a partir dos anos 2010, o fazer manual se encontra relacionado a necessidades pessoais do tempo e da contemplação, o que escapa de noções como o trabalho contínuo ou mesmo a emergência cotidiana. Assim como em sua popularização nos anos 1970, a busca por autonomia também é ligada a este movimento de retorno das artes manuais, no contexto tecnológico atual. Representa o desejo de escolher o que fazer e como fazer, adaptado para dinâmicas socioculturais contemporâneas, que são marcadas pela grande presença de ambientes digitais no dia a dia das pessoas. Segundo Cardoso ${ }^{17}$, a comunicação na atualidade alcança considerável padrão de instantaneidade, e há a possibilidade de realizar rápidas transições entre o material e o imaterial. Este cenário, aliado aos ambientes virtuais, torna favorável a propagação do "faça você mesmo" e das ideias atreladas ao movimento.

\section{Redes sociais, compartilhamento e consumo}

Para pensar nas redes sociais digitais, partimos da reflexão sobre a palavra redes que, associada ao corpo humano, foi utilizada ao longo dos anos em diversos contextos e campos como a medicina e a tecelagem. Pierre Musso ${ }^{18}$ aponta que o termo se tornou um conceito a partir do século XIX, quando deixou de ser associado ao corpo e passou a ser visto como um

\footnotetext{
${ }^{15}$ Meggs, P. B. História do design gráfico: Philip B. Meggs e Alston W. Purvis. São Paulo: Cosac Naify, 2009.

${ }^{16}$ BAHIA, A. B. Bordaduras na Arte contemporânea brasileira: Edith Derdyk, Lia
}

Menna Barreto e Leonilson. Artigo de conclusão de curso de especialização, Linguagem Plástica Contemporânea/UDESC. Florianópolis: Periscope Magazine, 2002.

${ }^{17}$ CARdoso, R. Design para um Mundo Complexo. São Paulo: Ubu, 2017.

${ }^{18}$ Musso, P. A filosofia da rede. In: PARENTE, André (Org.). Tramas da Rede. Novas dimensões filosóficas, estéticas e políticas da comunicação. Porto Alegre: Sulina, 2004. p.17-38. 
"artefato técnico"19 ${ }^{19}$, pensado em sua relação com o espaço e sendo capaz de entrelaçar questões. Assim, propõe que as redes podem ser criadas, construídas e redimensionadas.

Nos anos 1970, com a origem da sociedade da informação, onde os indivíduos passam a estar conectados de forma horizontal e em rede, estes conceitos ganham novos horizontes. Atualmente, pensar em redes é pensar em um ambiente de interconexões, que propõe experiências de interação e relações ${ }^{20}$. Dessa forma, dialogando com as tecnologias da informação, torna-se possível criar ambientes de compartilhamento e experimentação através das ferramentas digitais.

A construção de relações e difusão de informações por meio da sociedade em rede possibilitou que formas de criar coletivamente, como o "faça você mesmo", alcançassem novos públicos. São cada vez mais pessoas que consomem e produzem conteúdos relacionados a essas práticas, incentivando e promovendo ações pautadas na ideia de ensinar e aprender a fazer.

Nas redes sociais digitais é possível encontrar diversos conteúdos relacionados aos processos manuais de criação e artesanato. A plataforma Instagram concentra quase 70 milhões de postagens que utilizam a hashtag ${ }^{21}$ 'diy', mais de 25 milhões de conteúdos com a hashtag 'craft' (do inglês, artesanato), e mais de 15 milhões utilizam o termo 'artesanato 22 . Esses materiais são disponibilizados online através de vídeos, fotos, textos informativos, relatos e experiências.

No Youtube, o conteúdo sobre "faça você mesmo" possui, em sua maioria, o formato de vídeos-tutoriais. Os temas são diversos e compreendem vários níveis de habilidades, desde dicas básicas e sobre como iniciar as práticas, até os que exigem certo conhecimento dos usuários. Neles, é possível aprender e aprimorar técnicas através de passo-a-passos, conhecer materiais e entrar em contato com processos e produtores.

Similarmente, no Facebook, inúmeros grupos dialogam sobre artesanato e "faça você mesmo". Nesses espaços, os usuários compartilham informações e dicas, interagindo com os outros membros da comunidade. Também podemos observar diversos grupos intitulados 'Compre de quem faz', onde pessoas tanto procuram por produtos feitos artesanalmente, quanto compartilham seus trabalhos feitos de forma manual, personalizada e em pequenas quantidades. Desta forma, é possível perceber que, muitas vezes, a necessidade de aprender a fazer vem acompanhada por questões emergentes como o consumo consciente e a preocupação e/ou vontade de saber como as coisas são feitas.

Neste cenário, é fortalecida a ideia de economia criativa, um conceito que surgiu no final dos anos 1990 e se refere à comercialização de bens e serviços baseados na atividade criativa, habilidade e técnica. Miguez, coloca que são "produtos que incorporam propriedade intelectual e abarcam do artesanato tradicional às complexas cadeias produtivas das indústrias culturais" $^{23}$, ultrapassando o campo da cultura e se relacionando a outras áreas, como a economia. Os objetos criados dentro deste contexto da economia criativa são resultados do trabalho manual e intelectual, demonstrando a habilidade técnica de seus produtores.

Lipovetsky e Serroy ${ }^{24}$ comentam que, no estágio atual das relações socioeconômicas, busca-se cada vez mais um consumo cujo fim seja a construção pessoal, e não a compra em si. Há a necessidade de experiências agradáveis, afetivas e enriquecedoras, atribuindo sentido ao ato da compra. No ímpeto de uma busca por um consumo consciente e que traga significado, podemos citar o apoio a esta economia criativa, produtos locais e pequenos produtores. Em suma, há a recompensa emocional e satisfação pessoal em apoiar ideais como o da própria autonomia, ou a defesa de causas sociais por

${ }^{19}$ Ibidem, 2004. p. 22

${ }^{20}$ SALLES, C. Redes da criação: construção da obra de arte. Vinhedo: Ed.Horizonte, 2006.

${ }^{21}$ Hashtags são palavras-chaves utilizadas para identificar e direcionar acesso aos conteúdos disponibilizados nas redes sociais.

22 Dados retirados do Instagram. Data de acesso: 19/06/2021.

${ }^{23}$ MigUEZ, P. Economia criativa: uma discussão preliminar. In: NUSSBAUMER, Gisele (Org.). Teorias e políticas da cultura: visões multidisciplinares. Salvador: EDUFBA, 2007. p. 96-97

${ }^{24}$ Lipovetsky, G.; Serroy, J. A estetização do mundo: Viver na era do capitalismo artista. São Paulo: Companhia das Letras, 2015. 
meio destes produtos - como o feminismo, direitos LGBTQIA+, diversidade racial e a promoção da leitura.

A partir das possibilidades apontadas, compreendemos que o uso das redes favorece o consumidor destes conteúdos e possibilita, para aqueles que produzem, maior alcance e novos caminhos para a criação. Por esse motivo, o compartilhamento de processos de criação nas redes sociais vem se tornando uma prática frequente de artistas e designers que buscam utilizar o potencial dessas plataformas para criar ambientes dialógicos e colaborativos.

\section{Processos de criação manual compartilhados em rede}

Diante de um cenário onde artistas e designers se habituaram a divulgar seus trabalhos em plataformas digitais, é cada vez mais presente o compartilhamento dos bastidores da criação, tornando acessíveis os percursos do processo criativo. A exposição de fotografias, anotações, rascunhos ou mesmo relatos posteriores reforça a visão do artista em relação ao próprio trabalho e suas intenções - Salles coloca que, a partir do estudo dos chamados “documentos de processo" 25 , é possível conhecer o ponto de vista do autor, como ele se relaciona com o mundo e como pretende construir sua obra. Ao compartilhar esses processos, tornam-se evidentes questões como as dificuldades com o material, escolhas necessárias para o projeto e decisões que levaram o objeto a um estado em que o produtor o considera "apresentável" ao público. Esta dinâmica pode aproximar o produtor do próprio consumidor e, em alguns casos, confirmar a posição daquela criação dentro de estéticas específicas, ideais ou movimentos.

Aqui, entendemos os processos de criação como sistemas complexos, em constante mudança, que agregam em si contextos específicos de cada época. Dessa forma, as tecnologias e as mídias sociais são incorporadas por artistas e designers, possibilitando que seus processos sejam amplamente compartilhados e acessados por mais pessoas. Através dessas ferramentas digitais, há também o aumento das interações, responsáveis por criar caminhos e possibilidades que mantém as redes em expansão contínua ${ }^{26}$.

Alexandre Heberte, artista tecelão, é um exemplo de diálogo entre processos de criação manual e as redes. O artista dispõe de uma produção de tecelagem diversa e que atravessa diversos campos, como as artes, o design e a moda, possuindo a experimentação como uma característica marcante. Além do tradicional tear de pente liço, utiliza araras de metal, papelão, chassis, paredes para criar seus tecidos e tramas feitos à mão e incorpora em seus trabalhos materiais incomuns na tecelagem como fios, arame e objetos que seriam descartados.

Leão e Salles ${ }^{27}$ colocam que há um crescente interesse por processos de criação. Para as autoras, esses documentos de processos oferecem grande potencial de estudo tanto aos artistas, que fazem descobertas a partir dos próprios processos, quanto para os interessados nesses trabalhos. A curiosidade que esses produtos despertam aliada ao compartilhamento nas redes permite que as pessoas tenham acesso a como esses trabalhos são executados.

Desde que começou a tecer, Alexandre documenta seu processo criativo em plataformas e ferramentas digitais. No blog, Peixes em Peixes, registrou seus trabalhos através de fotos detalhadas e textos informativos sobre as peças que criou entre os anos de 2009 e 2020. Na plataforma Youtube ${ }^{28}$, o canal de Alexandre, que conta com mais de quatrocentas e trinta mil visualizações totais, reúne vídeos do artista tecendo nos diversos suportes, divulgação de projetos e exposições, além de registros das lives ${ }^{29}$ realizadas por ele. No Instagram, podemos encontrar fotos das obras, dos processos, conteúdo sobre suas exposições, oficinas e

\footnotetext{
${ }^{25}$ SALLES. Op. cit., 2008, p. 108

${ }^{26}$ SALLES, Op. cit., 2006.

${ }^{27}$ LEÃo, L; SAlLeS, C. A pesquisa em processos de criação nas mídias: três perspectivas. Rio de Janeiro. ANPAP, Congresso da Associação Nacional dos pesquisadores em artes plásticas, 2011.

${ }^{28}$ Disponível em: <youtube.com/c/AlexandreHeberte>. Acesso em: 22/06/2021.

${ }^{29}$ Vídeos realizados ao vivo pela plataforma.
} 
aulas. Seu perfil pessoal ${ }^{30}$ e página ${ }^{31}$ no Facebook funcionam como um arquivo de processos, em que é possível encontrar, nos mais de cento e sessenta álbuns de fotos, trabalhos desenvolvidos desde 2009.

Alinhado às questões que envolvem o imaginário da tecelagem e do fazer artesanal, Alexandre reforça em sua atuação a importância de espaços coletivos e de compartilhamento de saberes. A princípio, essa atuação se dava majoritariamente de forma presencial, através de cursos e aulas onde ensinava suas técnicas. O ensinar e o aprender são palavras chaves das produções artesanais e, a partir dessa ideia, as redes possibilitam também que essa prática se expanda. As redes sociais do artista são, mais do que um espaço para compartilhar, um ambiente de interação e troca constante. Através dos vídeos e lives realizados nas plataformas, Alexandre registra seus processos, dialoga sobre suas práticas, tira dúvidas e ensina a tecer (Fig. 1).

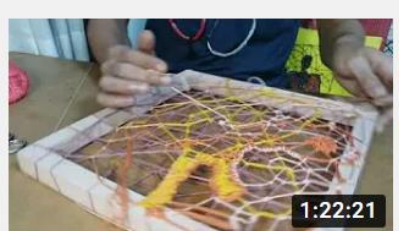

Trama no Chassis com Alexandre Heberte

62 visualizações · há 2 meses

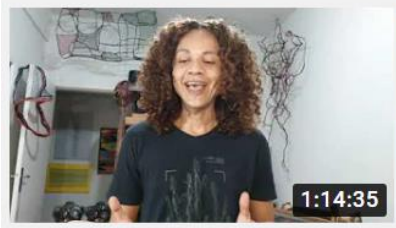

Trama de domingo com Alexandre Heberte

106 visualizações · há 3 meses

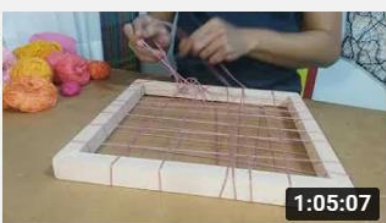

: Trama no chassis parte 1 141 visualizações · há 2 meses

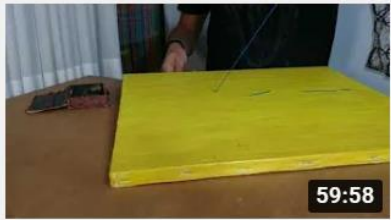

: Trama na tela com Alexandre Heberte

117 visualizações · há 3 meses

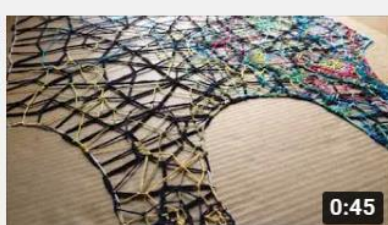

: Renda de tecelão 130 visualizações · há 2 meses

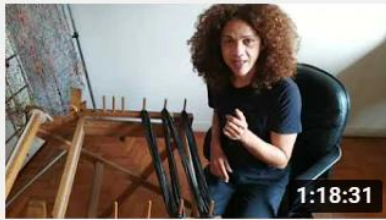

: Montagem do urdume com Alaxandre Heberte

258 visualizações · há 3 meses
Tear de papelão 129 visualizações · há 2 meses

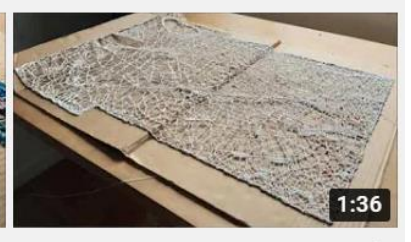

:

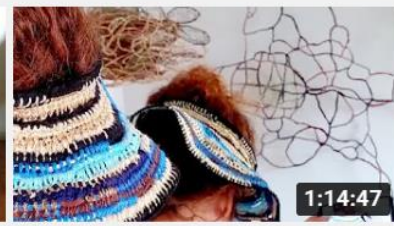

- Trama em Órbita com Alaxandre Heberte 99 visualizações · há 4 meses

Figura 1. Captura de tela da lista de vídeos do canal no YouTube de Alexandre Heberte, 2021. ${ }^{32}$

Além de artistas-artesãos, no ambiente das redes sociais podemos encontrar grupos e coletivos que fomentam a prática manual compartilhada, utilizando estas plataformas para promover diálogos sobre o fazer à mão. Dentre estes grupos, destacase o Clube do Bordado, iniciativa criada em 2013 por 6 mulheres que iniciaram sua atuação nas redes compartilhando seus próprios trabalhos e experiências com o bordado. Ultrapassando a ideia de um conhecimento técnico, o projeto objetiva a valorização e ressignificação da prática manual do bordado através de um trabalho que dialoga com questões contemporâneas, como o feminismo e o consumo consciente.

Em 2016, para além dos projetos pessoais desenvolvidos pelas autoras, o coletivo passou a criar e publicar conteúdos em um canal do Youtube ${ }^{33}$ (Fig. 2), que atualmente conta com quase duzentos mil inscritos e mais de sete milhões de visualizações totais. No canal, há vídeos tutoriais onde ensinam passo-a-passos, vídeos sobre indicação de materiais e onde conversam sobre assuntos diversos, que atravessam as questões levantadas pelo grupo. No Instagram ${ }^{34}$, possuem mais de duzentos e trinta mil seguidores e compartilham fotos e vídeos dos processos, projetos finalizados, textos informativos, além de repostarem

\footnotetext{
${ }^{30}$ Disponível em: <facebook.com/alexandre.heberte> Acesso em: 22/06/2021.

${ }^{31}$ Disponível em: <facebook.com/aleheberte>. Acesso em: 22/06/2021.

32 Disponível em: <youtube.com/c/AlexandreHeberte/videos>. Acesso em: 22/06/2021.

33 Disponível em <youtube.com/c/ClubedoBordado>. Acesso em: 25/06/2021.

${ }^{34}$ Disponível em <instagram.com/clubedobordado>. Acesso em: 25/06/2021.
} 
resultados e relatos dos trabalhos de quem acompanha o grupo.
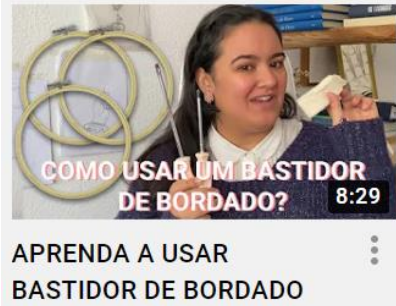

1,6 mil visualizações · há 2 dias

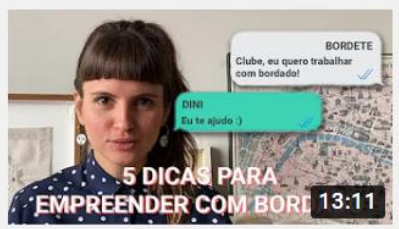

5 DICAS PARA EMPREENDER NO...

4,9 mil visualizações · há 1 mês

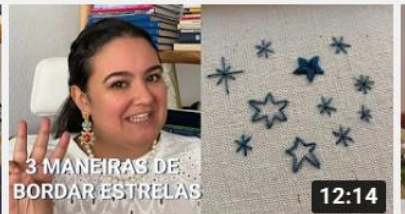

COMO BORDAR ESTRELAS

3 maneiras

2,8 mil visualizações •

há 1 semana

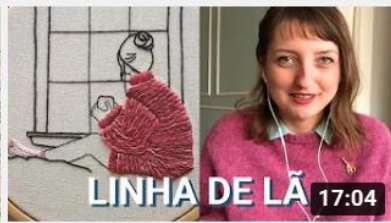

BORDADO COM LÃ \#108

7 mil visualizações · há 1 mês

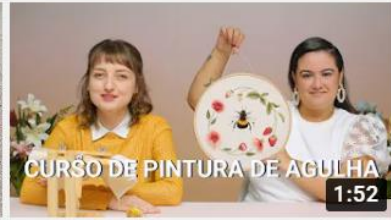

QUER APRENDER PINTURA DE AGULHA?

2,1 mil visualizações •

há 2 semanas

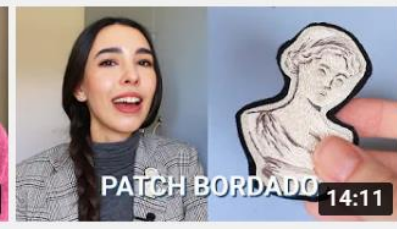

PATCH BORDADO \#107

7,8 mil visualizações . há 2 meses

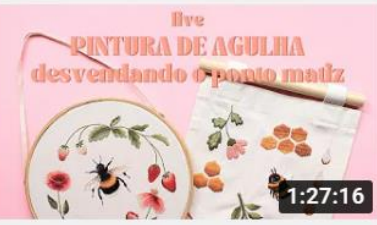

Boas Vindas ao CURSo PINTURA DE AGULHA:..

6,7 mil visualizações ·

Transmitido há 2 semanas

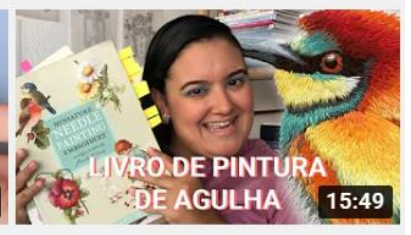

PINTURA DE AGULHA livros : de Trish Burr

6,7 mil visualizações • há 2 meses

Figura 2. Captura de tela da lista de vídeos do canal no YouTube do Clube do Bordado, 2021. ${ }^{35}$

Para o Clube do Bordado, a iniciativa de compartilhar conteúdos que ensinam e estimulam as pessoas a produzirem seus

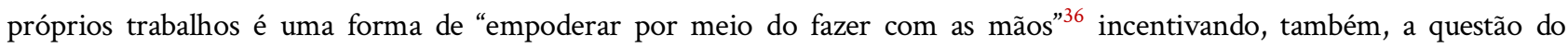
empreendedorismo feminino. Por meio dos conteúdos disponibilizados nas redes sociais, visam estimular a autonomia daqueles que assistem os vídeos-tutoriais e acompanham os processos do grupo, para que estes consumidores possam se tornar produtores e, até, comercializar os frutos do trabalho.

Quanto à questão da escolha de como produzir, podemos colocar que, no cenário editorial contemporâneo, as produções independentes representam a busca por estes processos autônomos, seguindo os rastros das zines dos anos 1970. Estas editoras costumam se distanciar das dinâmicas do mercado tradicional e, embora não desconsiderem questões mercantis, como o lucro, seu capital social está centrado na produção de edições primorosas, tanto no âmbito estético quanto no conteúdo. Busca-se a liberdade de escolha sobre o que publicar, meios de divulgação e tamanho das tiragens.

$\mathrm{Na}$ cena independente, é possível observar o processo que Muniz Jr. ${ }^{37}$ se refere como "reabilitação do impresso"38, o restabelecimento da cultura do impresso por meio da manualidade - a impressão com tipos móveis, encadernação artesanal e serigrafia -, visando exacerbar a materialidade do papel.

Ainda que haja a defesa da mídia física e do artesanal como um modo de fazer, é comum que estes produtores encarem o ambiente virtual tal qual uma ferramenta para divulgação de seus modos de criação, especialmente os que envolvem a manualidade. Podemos indicar que a demonstração de como se dá um processo feito à mão agrega valor ao objeto, pois reforça a ideia de que alguém dispôs atenção e trabalho àquela construção. Neste sentido, é de grande vantagem para estas editoras

\footnotetext{
${ }^{35}$ Disponível em: <youtube.com/c/ClubedoBordado/videos>. Acesso em: 25/06/2021.

${ }^{36}$ Clube do Bordado. Sobre o Clube do Bordado. Disponível em <oclubedobordado.com.br/>. Acesso em: 20/06/2021.

${ }^{37}$ MUNIZ JR., J. S. Girafas e bonsais: editores “independentes” na Argentina e no Brasil (1991-2015). 335f. Tese (doutorado em Sociologia) Orientador: Sergio Miceli Pessôa de Barros. Universidade de São Paulo, São Paulo, 2016.

${ }^{38}$ Ibidem, 2016, p. 197.
} 
documentar as etapas de fabricação de seus impressos, relatar e divulgar este processo.

No caso da Polvilho Edições (MG), a editora foi criada em 2012 por Ana Rocha, artista visual que escreve, edita e cria o projeto gráfico dos impressos. Busca-se seguir a linha editorial da publicação afetiva, artesanal e autoral, visando o desenvolvimento criativo da autora-editora. É um exemplo fortalecedor da ideia de autonomia, já que uma mesma pessoa realiza todas as atividades referentes à publicação e à distribuição.

Em ambiente virtual, a Polvilho costuma ser ativa na plataforma Instagram ${ }^{39}$, onde são compartilhados detalhes do processo, o andamento dos pedidos e novidades sobre a editora. Também são realizadas lives, geralmente à ocasião de feiras de publicações ou lançamento de impressos, iniciativas que favorecem o relacionamento com o público. As postagens costumam exibir e explorar a materialidade da publicação e as texturas do impresso.

Alguns dos compartilhamentos dizem respeito ao livro Jardim do Seu Neca, cuja primeira edição saiu em 2014 e foi reeditado em 2020. Dentre as imagens divulgadas, o registro das plantas que inspiraram a autora e viriam a basear as ilustrações da publicação (Fig. 3).

\footnotetext{
${ }^{39}$ Disponível em: <instagram.com/polvilho_edicoes>. Acesso em: 19/06/2021.
} 


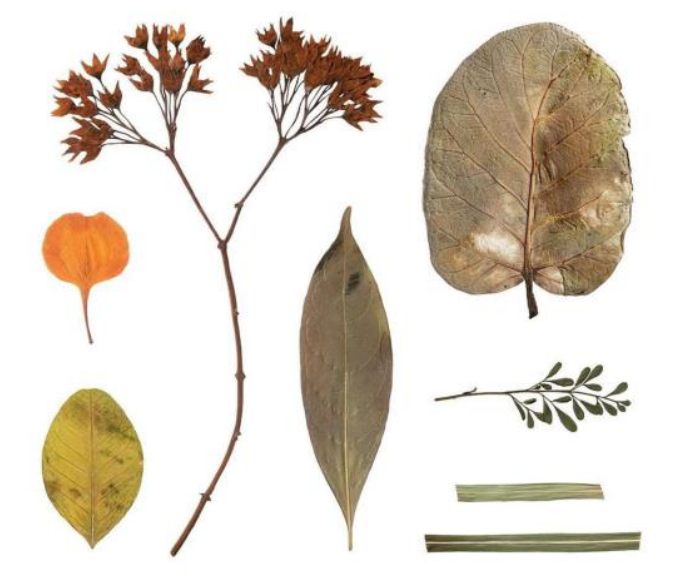

(

Figura 3. Captura de tela de post no Instagram onde se compartilha o material original que inspirou as ilustrações de capa de Jardim do Seu Neca, $2021^{40}$.

Ainda assim, o compartilhamento do processo criativo ocorre de forma mais ostensiva no site da editora ${ }^{41}$, onde existem espaços dedicados à sua história, motes, aparições na mídia (impressa e digital) e, finalmente, a loja contendo impressos e objetos gráficos adjacentes. No ambiente de compra, dispõem-se as habituais imagens dos produtos, descrição técnica e textos sobre o processo de fabricação, a motivação para a criação e outros. O que nos chama a atenção é que, para determinados impressos - como a primeira edição de Jardim do Seu Neca -, há também a extensa divulgação da concepção, impressão e construção física do livro, processos retratados em imagens (Figs. 4, 5 e 6).

\footnotetext{
${ }^{40}$ Disponível em: <instagram.com/p/CMpbgpznLsO>. Acesso em: 19/06/2021.

${ }^{41}$ Disponível em: <polvilhoedicoes.com>. Acesso em: 19/06/2021.
} 


\section{em processo}
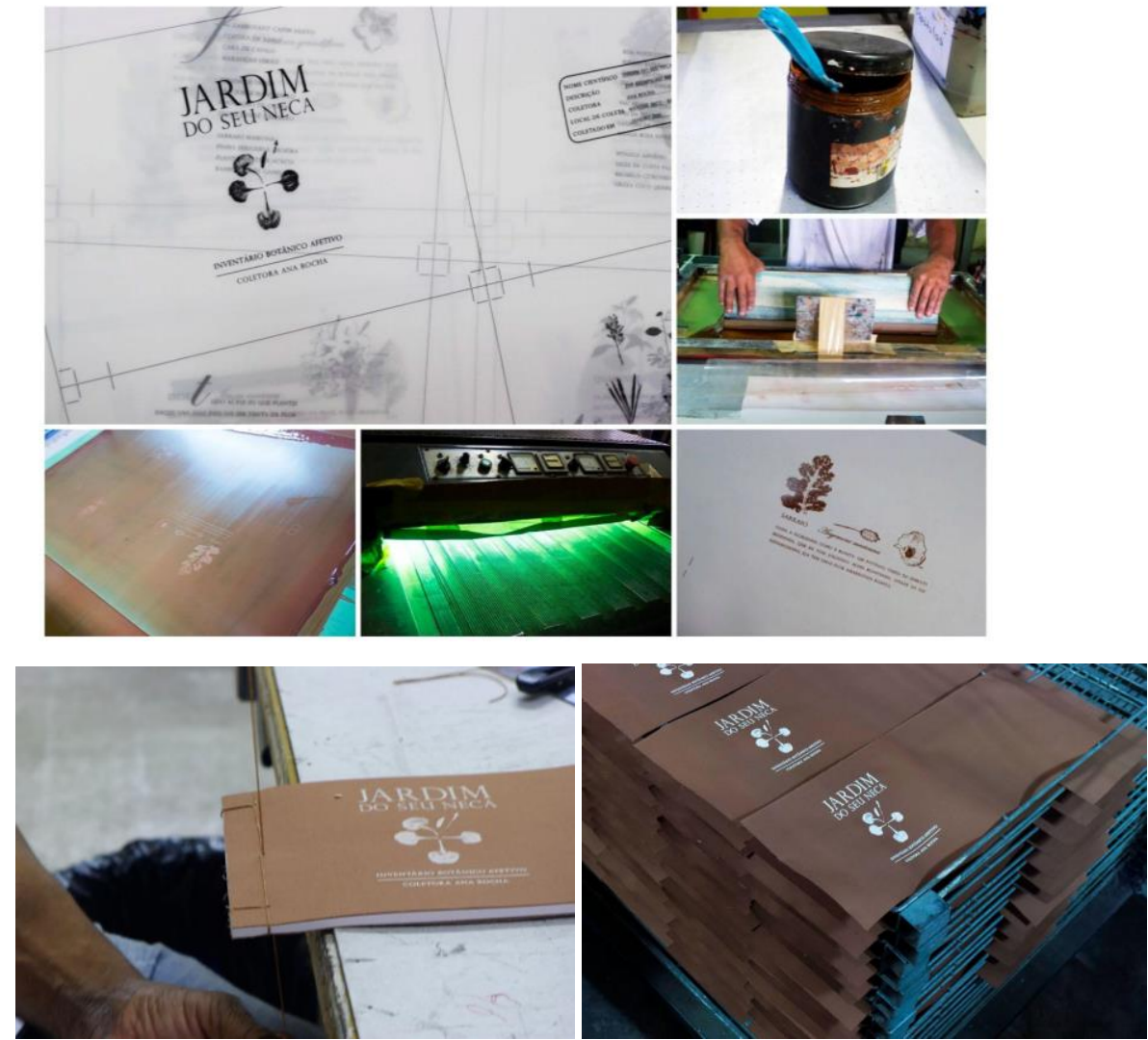

Figura 4, 5 e 6. Captura de tela e detalhes do processo de impressão e encadernação artesanal de Jardim do Seu Neca, divulgados no site da editora. ${ }^{42}$

Adicionando ao fato de que a autora-editora, Ana Rocha, costuma falar abertamente sobre seu processo, por meio de relatos e entrevistas ${ }^{43}$ em que explora suas motivações para o ato de publicar; podemos perceber que as redes e ambientes digitais ampliam as possibilidades de criação, exposição de seus produtos e difusão do ideal da edição independente.

\section{considerações finais}

A partir dos casos apresentados, pudemos observar que o compartilhamento do fazer manual em plataformas digitais, como redes sociais, sites e blogs, fornece aos produtores novas mecânicas de atuação, distribuição do trabalho e formação de vínculos com seus apoiadores-consumidores. Em campos distintos da produção artística e do design, o "faça você mesmo" representa a possibilidade de um fazer com atenção, autônomo e que, além disso, se conecta a questões emergentes contemporâneas, como a igualdade de gênero, o consumo ecologicamente aceitável e a individualização dos produtos e experiências.

\footnotetext{
42 Disponível em: <polvilhoedicoes.com/2014/10/06/em-processo-2>. Acesso em: 19/06/2021.

${ }^{43}$ Ver mais em: Na Mídia - Polvilho Edições. Disponível em: <polvilhoedicoes.com/na-midia>. Acesso em: 19/06/2021.
} 
Os exemplos se conectam à medida em que estes produtores parecem prezar pela escolha de como utilizar os materiais, como distribuir seus trabalhos e as possibilidades do compartilhamento em rede. Certamente, a proximidade que advém do ambiente virtual permite o desenvolvimento de relações humanas entre produtores e consumidores que, por meio da divulgação de minúcias dos projetos e da criação em si, podem se sentir como parte daquele processo.

Segundo Salles, "No estudo do processo de criação, ao apreender o surgimento e o desenvolvimento dos objetos artísticos, o pesquisador também participa da obra e surge, assim, um novo modo de apreender a arte" ${ }^{44}$. À medida em que propomos a investigação de processo dos exemplos que figuram neste trabalho, ainda que este estudo seja relativo a fatos passados, é possível compreender os procedimentos adotados por estes produtores ao longo do desenvolvimento de seus projetos, assim como as características destes processos que são compartilhadas em rede.

Até certo ponto, a autonomia é algo intrínseco a este modo-fazer. Embora o termo "diy" ou "faça você mesmo" não seja diretamente citado por estes artistas e produtores, não há dúvidas de que as práticas aqui colocadas remetem, invariavelmente, aos ideais do movimento. A formação de espaços de compartilhamento, ambientes e práticas coletivas e o diálogo com questões contemporâneas remonta o cenário que se popularizou nos anos 1970. Reforçamos, então, o caráter social do movimento que, atualmente, visa o fazer com as mãos em esferas da criação que permitem a lentidão do trabalho e a busca por um tempo não relacionado à emergência cotidiana ou noções de trabalho contínuo.

O fortalecimento desta economia criativa, baseada no trabalho criativo e intelectual, corresponde à atribuição de significado aos produtos que advém do esforço pessoal e trabalho manual daquele que o produz. Logo, reforçamos o papel das redes sociais e ambientes virtuais como agregadores de pessoas e interesses, permitindo que os agentes da cena interajam e troquem experiências apesar de possíveis distâncias físicas.

Apesar do caráter analógico dos trabalhos manuais, que não necessariamente dependem dessas tecnologias para existir, essas produções são inevitavelmente atravessadas pelos processos digitais que permitem a expansão de suas atuações; e a construção de um extenso arquivo de documentos de processo por meio dos diversos formatos digitais e plataformas de compartilhamento em rede.

\section{Referências bibliográficas}

BAHIA, Ana Beatriz. Bordaduras na Arte contemporânea brasileira: Edith Derdyk, Lia

Menna Barreto e Leonilson. Artigo de conclusão de curso de especialização, Linguagem Plástica Contemporânea/UDESC. Florianópolis: Periscope Magazine, 2002.

BORGES, Adélia. Design + Artesanato: o caminho brasileiro. São Paulo: Terceiro Nome, 2011.

CARDoso, Rafael. Design para um Mundo Complexo. São Paulo: Ubu, 2017.

CASTELS, Manuel. A sociedade em rede. São Paulo: Paz e Terra, 2016.

Clube do Bordado. Sobre o Clube do Bordado. Disponível em <oclubedobordado.com.br/>. Acesso em: 20/06/2021.

CRARY, Jonathan. 24/7 - Capitalismo tardio e os fins do sono. Sem paginação. São Paulo: Cosac Naify, 2014.

FLUSSER, Vilém. Filosofia da caixa preta: Ensaios para uma futura filosofia da fotografia. São Paulo: Annablume, 2011.

${ }^{44}$ SALLES, C. Op. cit., 2008, p. 32 
HAN, Byung-Chul. Sociedade do cansaço. Petrópolis: Vozes, 2015.

HARRIS, Richard. Building a Market: The Rise of the Home Improvement Industry, 1914-1960. Historical Studies of Urban America. Chicago: University of Chicago Press, 2012.

LEÃo, Lucia; SALlES, Cecília. A pesquisa em processos de criação nas mídias: três perspectivas. Rio de Janeiro. ANPAP, Congresso da Associação Nacional dos pesquisadores em artes plásticas, 2011.

Lipovetsky, Gilles; Serroy, Jean. A estetização do mundo: Viver na era do capitalismo artista. São Paulo: Companhia das Letras, 2015.

MEgGs, Philip B. História do design gráfico: Philip B. Meggs e Alston W. Purvis. São Paulo: Cosac Naify, 2009.

MiguEZ, Paulo. Economia criativa: uma discussão preliminar. In: NUSSBAUMER, Gisele (Org.). Teorias e políticas da cultura: visões multidisciplinares. Salvador: EDUFBA, 2007. p. 95-113.

Muniz JR., José de Souza. Girafas e bonsais: editores “independentes” na Argentina e no Brasil (1991-2015). 335f. Tese (doutorado em Sociologia) Orientador: Sergio Miceli Pessôa de Barros. Universidade de São Paulo, São Paulo, 2016.

Musso, Pierre. A filosofia da rede. In: PARENTE, André (Org.). Tramas da Rede. Novas dimensões filosóficas, estéticas e políticas da comunicação. Porto Alegre: Sulina, 2004. p.17-38.

SALLES, Cecília. Redes da criação: construção da obra de arte. Vinhedo: Ed.Horizonte, 2006.

SALLES, Cecília. Crítica genética:fundamentos dos estudos genéticos sobre o processo de criação. São Paulo: EDUC, 2008.

SENNETT, Richard. O Artífice. Rio de Janeiro: Record, 2009.

Recebido em: 27/06/2021

Aceito em: 04/10/2021 